\title{
A deficiência visual em foco: estratégias lúdicas na Educação Matemática Inclusiva
}

\author{
The visual impairment in focus: strategies playful in Inclusive Mathematics \\ Education
}

La deficiencia visual en pauta: estrategias lúdicas en la Educación Matemática Inclusiva

\section{Érica Santana Silveira Nery}

Doutoranda pela Universidade de Brasília, Distrito Federal, Brasília, Brasil.

erica.s.silveira@hotmail.com

ORCID - https://orcid.org/0000-0002-0571-1560

\section{Antônio Villar Marques de Sá}

Professor doutor na Universidade de Brasília, Distrito Federal, Brasília, Brasil.

villar@unb.br

ORCID - https://orcid.org/0000-0001-8815-9216

Recebido em 28 de outubro de 2018

Aprovado em 24 de agosto de 2019

Publicado em 12 de novembro de 2019

\section{RESUMO}

O objetivo deste artigo é discutir sobre o ensino de Matemática para alunos com deficiência visual, apontando expressões lúdicas enquanto estratégia de ensino no âmbito da inclusão escolar. As expressões lúdicas podem compor-se de jogos, brincadeiras e outras atividades que venham a despertar o espírito lúdico nos sujeitos que as realizam. A partir dos estudos aqui analisados e da identificação de jogos pedagógicos táteis e digitais, acredito que os materiais considerados lúdicos podem contribuir para o desenvolvimento do sistema háptico ou tato ativo, uma vez que, através deste sistema, os indivíduos sem acuidade visual percebem o mundo ao seu redor e podem construir diferentes conceitos matemáticos, potencializando a aprendizagem neste componente curricular. Por este motivo, serão descritos diferentes materiais e jogos que possibilitem tratar conteúdos matemáticos presentes na Educação Básica, especialmente aqueles construídos e testados junto a alunos cegos e com baixa visão. Os resultados apontam para a necessidade de realizar mais pesquisas que apresentem outras alternativas lúdicas, para o desenvolvimento do processo de ensino e aprendizagem de conceitos matemáticos pouco contemplados em tais materiais ou jogos. Em sua maioria, as atividades abordam conceitos de função, geometria, progressão geométrica, as quatro operações básicas, e o reconhecimento dos símbolos que representam os números. Entretanto, há inúmeros outros conteúdos matemáticos que ainda são trabalhados em sala de aula com um forte apelo visual, demandando outras estratégias que favorecem a inclusão e aprendizagem de pessoas com deficiência visual.

Palavras-chave: Educação Matemática Inclusiva; Expressões lúdicas; Deficiência visual. 
http://dx.doi.org/10.5902/1984686X35402

\begin{abstract}
This paper aims to argue on teaching Mathematics with visual impairment students, to aim playful expression as strategy of teaching at the scope of school inclusion. The expression. playful can be composed of games, horseplay, as well as other activities that might evoke the playful spirit in the individuals who are likely do them. From the studies here submitted, and the identification of tactile and digital pedagogical games, we believe that those materials which are considered ludic may contribute to the development of the haptic system or active touch, since through this system, individuals without visual acuity perceive the world around them and can build different concepts of Mathematics, boosting the learning in this curricular component. For this reason, different materials and games that allow to treat mathematical contents present in Basic Education will be described, especially those built and tested with blind and low sight students. The results indicate the need to accomplish more researches that may present other ludic alternatives for the development of teaching and learning process of mathematical concepts, little exploited in such materials or games. Once the majority of the activities present concepts of geometry, the four basic Mathematical operations, recognition of numerical symbols, geometric progression and function. However, there are countless other mathematical contents that are still part of today's classroom with a strong visual appeal, demanding other strategies that favor the inclusion and learning of people with visual impairment.
\end{abstract}

Keywords: Inclusive Mathematics Education; Expression playful; Visual impairment.

\title{
RESUMEN
}

El objetivo de este artículo es discutir sobre la enseñanza de las Matemáticas para alumnos con discapacidad visual, señalando expresiones lúdicas como estrategia de enseñanza en el ámbito de la inclusión escolar. Las expresiones lúdicas pueden componerse de juegos, entretenimientos y otras actividades que inciten el espíritu lúdico en los sujetos que las realizan. A partir de los estudios aquí analizados y de la identificación de juegos pedagógicos táctiles y digitales, pienso que los materiales considerados lúdicos pueden contribuir al desarrollo del sistema háptico o tacto activo, ya que, a través de este sistema, los individuos sin agudeza visual perciben el mundo a su alrededor y pueden construir diferentes conceptos matemáticos, potenciando el aprendizaje en este componente curricular. Por este motivo, se describen diferentes materiales y juegos que posibiliten tratar contenidos matemáticos presentes en la Educación Básica, especialmente aquellos construidos y probados junto a alumnos ciegos y con baja visión. Los resultados apuntan a la necesidad de realizar más investigaciones que presenten otras alternativas lúdicas para el desarrollo del proceso de enseñanza y aprendizaje de conceptos matemáticos poco contemplados en dichos materiales o juegos. En su mayoría, las actividades abordan conceptos de función, geometría, progresión geométrica, las cuatro operaciones básicas, y el reconocimiento de los símbolos que representan los números. No obstante, hay innumerables otros contenidos matemáticos que todavía son trabajados en el aula con un fuerte atractivo visual, demandando otras estrategias que favorecen la inclusión y el aprendizaje de personas con discapacidad visual.

Palabras clave: Educación Matemática Inclusiva; Expresiones lúdicas; Deficiencia visual. 
http://dx.doi.org/10.5902/1984686X35402

\section{Introdução}

Vivemos em uma cultura de videntes, em que a maioria das interações sociais são percebidas pelo sistema visual, fato observado por Siaulys (2010) ao mencionar que $80 \%$ das informações que recebemos no dia-a-dia são fornecidas por meio da visão. Ao discutir sobre tal questão, Sá (2004) aponta a necessidade de se valorizar os vários canais de percepção do ser humano, com o intuito de depreender sobre a existência dos outros órgãos do sentido que nos possibilitam compreender, perceber e construir a visão de mundo, ao nosso redor tão próximo ao real, quanto se possa imaginar.

As discussões que aqui serão tecidas são de suma importância, tendo em vista que a Organização Mundial de Saúde (OMS) tornou público, em 2011, que o número de casos de deficientes visuais era estimado em 285 milhões de pessoas no mundo, dos quais 39 milhões são cegas. A previsão é que o número atual de cegos no planeta alcance 76 milhões em 2020 (ÁVILA et al., 2015). No cenário brasileiro, a deficiência visual é a mais constatada, segundo dados do Censo de 2010, do Instituto Brasileiro de Geografia e Estatística (IBGE), a deficiência visual está presente em 16,0\% dos homens e 21,4\% das mulheres, atingindo cerca de 35,8 milhões de pessoas. Segundo dados do censo da Educação Básica, realizado em 2016 (BRASIL, 2016), do total de 971.372 alunos da educação especial matriculadas em escolas especializadas e regulares, 76.470 são cegos, surdocegos ou têm baixa visão. Ressaltamos de acordo com o Decreto no 5.296/2004 que a deficiência visual inclui:

[...] cegueira, na qual a acuidade visual é igual ou menor que 0,05 no melhor olho, com a melhor correção óptica; a baixa visão, que significa acuidade visual entre 0,3 e 0,05 no melhor olho, com a melhor correção óptica; os casos nos quais a somatória da medida do campo visual em ambos os olhos for igual ou menor que $60^{\circ}$; ou a ocorrência simultânea de quaisquer das condições anteriores (BRASIL, 2004, p.1).

Vale destacar que o cenário educacional brasileiro com vistas a inclusão melhorou, isto fruto de mudanças impulsionadas em âmbito nacional e internacional, as quais culminaram, por exemplo, na criação da Política Nacional de Educação Especial na Perspectiva Inclusiva (BRASIL, 2008), além disso, na garantia da matrícula, do financiamento público e dos recursos de acessibilidade em escolas regulares. Entretanto, isto não significa dizer que os nossos problemas históricos quanto à garantia do direito à educação aos estudantes com deficiência foram resolvidos (MANTOAN, 2015). Destarte, a educação para todos ainda é um desafio político e pedagógico a ser conquistado, pois uma 
http://dx.doi.org/10.5902/1984686X35402

grande parcela dos sujeitos com Necessidades Educacionais Específicas (NEE) ainda se encontram excluídos do sistema educacional mesmo com a garantia da educação inclusiva em leis. Isto pelo fato de estarmos considerando que o acesso à educação, em termos de inclusão, vai além do ato da matrícula, perpassando pela apropriação do saber e das oportunidades educacionais oferecidas (BRASIL, 1998) como garantia ao direito de aprendizagem.

Tendo em vista que não basta apenas que os alunos com deficiência estejam na escola para adaptar-se a ela, é necessário que as escolas acolham os alunos e estejam aptas para se adaptarem às suas necessidades e singularidades. Neste sentido, as escolas regulares devem buscar a superação dos modelos educativos que estejam pautados em uma homogeneidade, combatendo práticas segregadoras de ensino, e do mesmo modo contribuindo com a construção de uma sociedade inclusiva que desmistifique a ideia de normalidade e o discurso homogeneizante da igualdade que nega a diferença e a diversidade. Neste contexto, Mantoan (2015, p. 64) ao discutir sobre escola inclusiva propõe:

- Recriar o modelo educativo escolar, tendo como eixo o ensino para todos.

- Reorganizar pedagogicamente as escolas, abrindo espaço para a cooperação, o diálogo, a solidariedade, a criatividade e o espírito crítico sejam exercitados nas salas de aulas por professores, gestores, funcionários e alunos, porque essas são habilidades mínimas para o exercício da cidadania. Garantir aos alunos tempo e liberdade para aprender, bem como um ensino que não exclui nem só reprova a repetência.

- Formar, aperfeiçoar e valorizar o professor, a fim de que tenha condições e estímulo para enfrentar um ensino sem exclusões e exceções.

Neste sentido, a construção de escolas inclusivas demanda ações políticas, pedagógicas e institucionais que venham favorecer à participação e atuação dos diferentes sujeitos, de maneira a potencializar o princípio da democracia e o exercício da cidadania. Por conseguinte, faz-se necessário que sejam incentivadas atitudes que possam vir a favorecer o reconhecimento, pelos alunos, da sua cidadania, dos seus direitos e deveres, para que fora do ambiente escolar eles possam buscar o atendimento e o respeito as suas singularidades e a valorização da diversidade humana, enquanto princípio fundante de uma sociedade inclusiva.

No âmbito pedagógico, as principais ações podem ser descritas nos Projetos Políticos Pedagógicos das instituições de ensino, para que os gestores, professores, coordenadores 
e funcionários sejam esclarecidos sobre os recursos humanos e materiais que a instituição dispõe e que podem auxiliar no trabalho pedagógico em sala de aula e, para além disso, no processo de inclusão escolar de todos os alunos. Além disso, poderá ter considerações relacionadas à avaliação, à interdisciplinaridade, às práticas de ensino e o currículo (MANTOAN, 2015). Tais descrições poderão compor ações inclusivas essenciais para a efetivação de uma escola democrática e participativa, aberta à diferença e à diversidade, contemplando as necessidades, singularidades e potencialidades de cada sujeito.

Ademais, outras ações que são mais direcionadas ao espaço da sala de aula, mas que possuem uma abrangência que vai além desse contexto, são as adaptações de materiais didáticos que possam vir a atender os alunos, considerando-se suas especificidades, diferenças e singularidades. Tais adaptações constituem as adaptações de pequeno porte (BRASIL, 2005) as quais estão mais direcionadas à ação do professor frente ao aluno e a sua necessidade.

Nesse ínterim, concordamos com Masini (2013) ao mencionar que a pessoa com deficiência visual tem possibilidade de através de movimentos e interações com o derredor, construir suas habilidades de perceber, experienciar, organizar e compreender o mundo, como qualquer outra pessoa, tendo em vista a sua própria maneira de incorporar e interpretar o contexto que a rodeia. Esta compreensão em relação à deficiência visual e o próprio modo como a sociedade lida com essa questão demanda da educação alargar seu campo de percepção e atuação, oportunizando outras formas de interação que considerem a singularidade de tal sujeito.

Ao considerarmos os diversos órgãos do sentido na percepção de mundo, estamos a caminho de ultrapassar fronteiras, buscando novas maneiras de compreensão e de construção do conhecimento, posto que aprendemos de diversos modos para além do apelo visual que a sociedade, muitas vezes, acaba impondo. Com isso, pode se oportunizar que a pessoa com deficiência visual interaja com o universo educacional de maneira mais efetiva, e do mesmo modo interprete o contexto social e cultural com maior nitidez e sutileza, para além da percepção visual.

O cenário aqui brevemente problematizado aponta para a inclusão como um desafio ainda a ser alcançado pela educação e pela escola, inclusive no âmbito da prática pedagógica uma vez que muitos professores do ensino regular mencionam que não estão preparados para ensinar a todos os alunos (MANTOAN, 2015). Assim, este artigo tem como 
http://dx.doi.org/10.5902/1984686X35402

objetivo discutir sobre o ensino de Matemática para alunos com deficiência visual, apontando expressões lúdicas enquanto estratégia de ensino no âmbito da inclusão escolar.

Para alcançarmos o objetivo aqui proposto, o presente texto foi organizado do seguinte modo: a) inicialmente discorre sobre ludicidade enquanto estratégia para o ensino e a aprendizagem Matemática no contexto da inclusão da pessoa com deficiência visual; b) em seguida aborda sobre as orientações presentes nas cartilhas denominadas de Projeto Escola Viva, com ênfase nas adaptações curriculares e suas correlações com a ludicidade; c) por fim apresenta e descreve sugestões lúdicas para o ensino da matemática com aluno cego e com baixa visão.

\section{Caminhando em busca de uma alternativa: a Ludicidade}

A presença da ludicidade na educação não é um fenômeno recente. Segundo Almeida (1998), sua presença percorre várias épocas, povos, bem como está presente no contexto de inúmeras pesquisas. Isto possibilitou uma vasta rede de conhecimentos que foi construída e divulgada no âmbito acadêmico. Assim, desde a época de Platão (427 a.C. 347 a.C) já se defendia a ideia de que as atividades lúdicas deveriam compor o cenário educativo destinado às crianças pequenas, numa perspectiva que não incentivasse a competição entre os alunos (HUIZINGA, 2014). No âmbito da educação de crianças com NEE, foi sobretudo a partir dos estudos de Maria Montessori, isto já no século XX, que a valorização de expressões lúdicas, tais como o brincar e o uso de jogos, no processo de ensino e aprendizagem, comparece enquanto estratégias exitosas para crianças com deficiência mental, isto objetivando a implementação da educação sensorial.

Vale ressaltar que ao nos reportarmos à concepção de lúdico podemos relacioná-la, em um primeiro momento, a atividades como jogos, brincadeiras e outras formas de lazer. Entretanto, cabe ressaltar que o conceito de ludicidade é mais amplo e envolve sensações de alegria, satisfação, contentamento, superação, prazer, diversão e liberdade. Neste contexto, a ludicidade não pode ser considerada uma característica específica de um dado objeto, seja este jogo, brincadeira ou outra forma de expressão, isso pelo fato de que por despertar algumas sensações nos indivíduos envolvidos, tais atividades podem não se configurarem lúdicas, seja pelo momento, meio ou por questões afetivas e sentimentais dos próprios sujeitos que as executam (LUCKESI, 2014). 
http://dx.doi.org/10.5902/1984686X35402

Destarte, a concepção de ludicidade é complexa e subjetiva, pois depende diretamente da relação estabelecida entre o sujeito, o objeto e o meio em que a atividade está inserida, entretanto, há algumas características destacadas por Macedo, Petty e Passos (2005) que caracterizam a presença do lúdico em uma determinada atividade, são estas: ter prazer funcional, ser desafiadora, criar possibilidades ou dispor delas, possuir uma dimensão simbólica e, por último, expressar-se de modo construtivo ou relacional.

A primeira característica refere-se a ter prazer funcional. Tal característica está pouco presente no contexto escolar, uma vez que os conteúdos são trabalhados como algo necessário aos alunos num futuro próximo, muitas vezes distantes do cotidiano e de uma realidade mais imediata e significativa, gerando, muitas vezes, desinteresse. Para os alunos, sobretudo as crianças, o que vale a pena é o prazer funcional, isto é, a alegria de exercitar certo domínio, de testar habilidades, enfim, de transpor obstáculos ou de vencer desafios (MACEDO; PETTY; PASSOS, 2005). Este primeiro aspecto da atividade lúdica sugere que ela envolve uma relação da criança ou adulto com uma tarefa, atividade ou pessoa, caracterizando-se pelo prazer funcional que ela desperta, isto é, a motivação tornase algo intrínseco e desenvolve-se a atividade pelo sentido de prazer que ela evoca e proporciona.

Outro atributo de uma atividade lúdica refere-se ao seu caráter desafiador e surpreendente, isto é, algo que nos chama atenção, nos surpreende, causa espanto e ao mesmo tempo nos desperta interesse, "nos pega por sua surpresa, pelo gosto de repetir em outro contexto" (MACEDO; PETTY; PASSOS, 2005, p. 19). No âmbito do surpreendente, podemos destacar que na realização de atividades lúdicas "não se controla todo o resultado, que algo tem sentido de investigação, de curiosidade, de permissão para a pessoa dizer o que pensa ou sente, de expressar suas hipóteses" (MACEDO; PETTY; PASSOS, 2005, p. 19). Segundo Macedo, Petty e Passos (2005), qualquer atividade poderá ser interessante, depende de como será proposta, do contexto em que estará inserida, das pessoas e do sentido que Ihes será atribuída pelos sujeitos envolvidos.

A terceira característica diz respeito à atividade lúdica enquanto um campo de possibilidades, que serão criadas ou validadas de experiências anteriores. Nesta conjuntura, destaca-se o fato das atividades serem necessárias e possíveis. O aspecto necessário, pode ser compreendido em dois pontos de vista distintos: o primeiro deles diz respeito ao fato de que a não realização da atividade lúdica pode produzir algum 
desconforto, como um sentimento de perda, um desejo ou demanda não atendida, este ponto relaciona-se a aspectos de cunho afetivos; já o segundo ponto de vista relaciona-se a aspectos cognitivos, isto é, na medida em que a atividade constitui-se como algo necessário, ela tem de ser minimamente possível de ser realizada (MACEDO; PETTY; PASSOS, 2005). A atividade será possível, na medida em que as crianças ou os adultos tenham habilidades ou Ihes sejam favorecidas condições que venham a possibilitar-lhes desenvolverem competências para realizá-la, bem como sejam oferecidos recursos externos, tais como, objetos materiais, espaços, pessoas ou tempo suficiente para tal realização.

Além disso, a presença do lúdico na aprendizagem pode ainda ser identificada pelo fato da atividade possuir uma dimensão simbólica. Nesta perspectiva, as atividades são caracterizadas como motivadas e históricas, tal como no exemplo apresentado por Macedo, Petty e Passos (2005): uma criança ao brincar de casinha atribui sentido aos objetos utilizados para montar o cenário, simula pessoas e acontecimentos, cria situações para que sua brincadeira tenha um sentido próprio, expressando seus desejos, sentimentos, valores. Tais aspectos inserem a atividade e a própria criança em um dado contexto cultural, ou seja, na dimensão simbólica.

A quinta característica é o expressar-se de modo construtivo ou relacional, o que implica considerar a atividade como sendo fruto da construção do próprio sujeito, segundo diversos pontos de vista. Assim, destaca-se como sendo parte de uma atividade lúdica um olhar atento, aberto e disponível para as muitas possibilidades de expressão (MACEDO; PETTY; PASSOS, 2005).

Desta maneira, a ludicidade é considerada "como algo inerente ao indivíduo e como um momento de lazer e prazer, onde a atividade é encarada de forma espontânea" (PIN, 2016, p. 31). Assim, fica evidente a necessidade de as escolas abrirem suas portas para incorporar a ludicidade como sendo um princípio pedagógico que venha a ser contemplado nas mais variadas áreas do conhecimento. No contexto específico da Matemática, acreditamos que é possível planejar atividades objetivando despertar nos alunos o espírito lúdico, tornando-as mais desafiadoras, prazerosas, instigantes e participativas, possibilitando que os alunos sejam os atores principais no processo de ensino e aprendizagem dos conteúdos matemáticos. 
http://dx.doi.org/10.5902/1984686X35402

Defendemos a utilização de atividades lúdicas na educação de crianças, jovens ou adultos com alguma deficiência, de maneira mais específica, neste artigo, das pessoas com deficiência visual, isto por concordarmos com Almeida (1998) ao mencionar que a verdadeira educação é aquela que cria no aluno o melhor comportamento, com o intuito de satisfazer suas múltiplas necessidades, isto é, necessidade de saber, explorar, jogar, viver, conviver e atuar na sociedade, e isto a ludicidade pode contribuir efetivamente, tendo em vista que:

A educação lúdica integra uma teoria profunda e uma prática atuante. Seus objetivos, além de explicar as relações múltiplas do ser humano em seu contexto histórico, social, cultural, psicológico, enfatizam a libertação das relações pessoais passivas, técnicas para as relações reflexivas, criadoras, inteligentes, socializadoras, fazendo do ato de educar um compromisso consciente intencional, de esforço, sem perder o caráter de prazer, de satisfação individual e modificador da sociedade (ALMEIDA, 1998, p. 30).

Deste modo, a educação lúdica vem ao encontro dos aspectos preponderantes da educação inclusiva, isto ao possibilitar uma mudança de perspectiva no ensino, em que o foco não se encontra apenas no conteúdo, mas também envolve o prazer e o aspecto desafiador que o desenvolvimento da atividade pode despertar no aluno. Assim, as atividades lúdicas ocasionam uma libertação das relações pessoais passivas, requerendo o desenvolvimento de relações reflexivas, criadoras e inteligentes, acarretando possivelmente uma postura mais atuante e efetiva nas relações sociais. Tal postura não é uma especificidade dos alunos com deficiência visual e sim de todos aqueles que possam vir a experimentar práticas de educação lúdica, as quais tenham sido preparadas de maneira intencional, objetivando a satisfação e o desenvolvimento do prazer em sua correlação com a aprendizagem.

\section{Caminhos cruzados: Atividades Lúdicas e Adaptações Curriculares}

Acreditamos que materiais lúdicos podem contribuir para o desenvolvimento do sistema háptico ou tato ativo, uma vez que através deste sistema os indivíduos sem acuidade visual percebem o mundo ao seu redor. Tendo em vista a necessidade de criação de materiais didáticos e possíveis adaptações necessárias que as instituições de ensino devem fazer para que possam receber alunos com as mais variadas necessidades educacionais, foram elaboradas diversas cartilhas nomeadas por Projeto Escola Viva, cujo objetivo é "favorecer a reflexão crítica sobre o ensino na diversidade, e de apresentar um 
conjunto de informações importantes para reconhecer e responder às diferentes necessidades educacionais" (BRASIL, 2005, p. 5). Ademais, estas cartilhas abordam sobre a necessidade de os educadores realizarem adaptações curriculares, com o intuito de atender as diversas necessidades educacionais presentes em sala de aula.

As adaptações curriculares são definidas, no Projeto Escola Viva, como "respostas educativas que devem ser dadas pelo sistema educacional, de forma a favorecer a todos os alunos e, dentre estes, os que apresentam necessidades educacionais especiais" (BRASIL, 2000, p. 9). Neste documento, são referendadas duas modalidades de Adaptações Curriculares: as Adaptações Curriculares de Grande Porte e as Adaptações Curriculares de Pequeno Porte, cuja finalidade é elucidar competências, atribuições e ações envolvidas na busca pela construção de um sistema educativo inclusivo.

Vale ressaltar que as Adaptações Curriculares de Grande Porte compreendem ações das instâncias político-administrativas superiores, exigindo modificações que envolvem ações de natureza política, administrativa, financeira e burocrática (BRASIL, 2000). As Adaptações Curriculares de Pequeno Porte são consideradas modificações a serem desenvolvidas pelos professores, configurando-se, assim, em pequenos ajustes nas ações planejadas a serem desenvolvidas no contexto da sala de aula e que perpassam pelos currículos (BRASIL, 2000).

Desse modo, fica a cargo do professor a criação de situações e o favorecimento da participação de todos os alunos nas aulas, com o intuito de reconhecê-los como iguais perante o direito de aprender e diferentes nas suas formas de interação e construção do conhecimento. Assim, ressalta-se a importância das adaptações curriculares por se constituírem como um direito dos alunos e, por conseguinte, um dever dos sistemas educacionais, de modo que não se busca a construção de um currículo paralelo para os alunos com NEE, mas sim um currículo inclusivo que tenha lugar para contemplar a todos os alunos em sala de aula.

De acordo com Siaulys (2010, p. 317), "as crianças com deficiência visual necessitam de estímulos diferenciados para o seu desenvolvimento sensório-motor, com oportunidades de interação, brincadeiras, brinquedos e materiais especiais adaptados". Isto vem ao encontro daquilo que defendemos neste texto por acreditarmos que a presença de brincadeiras, brinquedos e jogos, enquanto expressões lúdicas, configure uma 
possibilidade para que as crianças cegas e com baixa visão se reconheçam enquanto sujeitos sociais e aprendentes.

Os materiais adaptados, por exemplo, um livro de história infantil, impresso em tinta e Braille com desenhos em alto relevo, ou ainda, maquetes táteis, podem ser construídos de maneira que possam ser percebidos pelos outros órgãos do sentido que não o visual. Para Siaulys (2010), eles poderão ajudar a criança com deficiência visual a desenvolver a coordenação motora, adquirir a noção de forma, grandeza, peso, reconhecer texturas, estabelecer relações das partes com o todo, adquirir a noção de causalidade, sequência lógica, seriação, classificação, noções de quantidade, pensamento lógico-matemático, aprender a representar os objetos tridimensionalmente em massinha ou argila e representálos graficamente em relevo.

Destarte, apresentaremos na próxima seção algumas sugestões de atividades lúdicas que resultam de pesquisas planejadas e executadas junto a alunos cegos e com baixa visão, na perspectiva de contribuir com o processo de ensino e aprendizagem de conceitos matemáticos no contexto da inclusão.

\section{Um caminho de expressões lúdicas que leva ao ensino de Matemática}

Dentre os desafios que necessitamos superar no âmbito da Educação Matemática está o de desenvolver um ensino que possa incluir todos os alunos com as mais variadas especificidades existentes em sala de aula regular. Em consonância com o atual debate que vem sendo instaurado no âmbito da educação inclusiva, Moreira (2014, p. 40) destaca que muitos professores "embora atuando com alunos com dificuldades de aprendizagem ou com NEE, sentem-se despreparados para a prática docente, como se tivessem que ter cuidados diferenciados em relação àquelas crianças com desenvolvimento típico". Isso corrobora com a perspectiva de que incluir não significa apenas propor atividades diferenciadas, mas sim possibilitar oportunidades iguais e práticas diversas que possam contemplar os alunos em suas singularidades e diferenças, concebendo a aprendizagem em sua heterogeneidade.

Neste contexto, cabe ao professor buscar subsidiar sua prática docente com atividades que favoreçam a inclusão. Moreira (2014) defende que as atividades desenvolvidas em sala de aula regular devem ter um sentido prático, significativo e prazeroso para os alunos. Além disso, podem ser desenvolvidas em duplas, grupos que 
envolvam alunos com NEE, para que juntos possam aprender e ensinar os conteúdos matemáticos que estão estudando.

Vale ressaltar que apresentaremos, a seguir, atividades lúdicas que podem envolver a participação de todos os alunos, sejam cegos, com baixa visão ou videntes. Disto depende a maneira como serão propostas e dos objetivos previamente determinados pelos docentes. Entretanto, alguns pesquisadores já testaram e destacaram aspectos que as caracterizam como lúdicas. O primeiro material que apresentaremos é nomeado de Mosaico geométrico, representado na Figura 1.

Figura 1 - Mosaico Geométrico

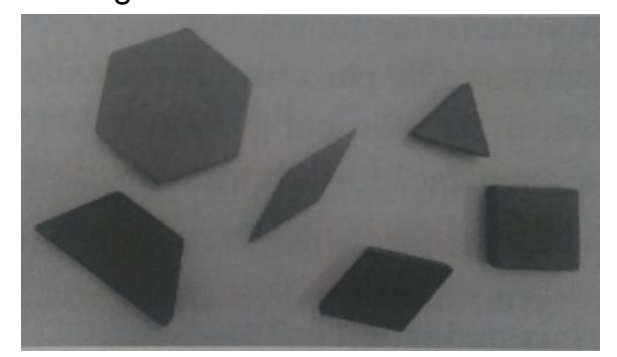

Fonte: Morgado, Santos e Takinaga (2016, p. 95).

Este mosaico pode despertar a criatividade e a imaginação, tendo em vista a possibilidade de criação, modificação e verificação de propriedades de figuras geométricas, utilizando como base para construção o quadrado, trapézio, losango, triângulo e/ou o hexágono, conforme Figura 1. Morgado, Santos e Takinaga (2016) sugerem, ainda, no âmbito de sua utilização numa perspectiva lúdica, a elaboração de painéis e a criação de histórias com personagens construídos com as peças do mosaico.

Outros materiais que podem ser destacados, são: tangram (quebra-cabeça bidimensional, em cinco formas diferentes), cubo soma, torre de Hanói, cubo mágico. Em relação a tais materiais, Cunha e Franco (2016) destacam que foram utilizados em oficinas que ocorreram entre os meses de março de 2014 e maio de 2015, com a participação de alunos de várias idades, desde o Ensino Fundamental até o Ensino Superior, além de alunos deficientes visuais de duas escolas como parte integrante do Museu Itinerante de Neurociências. Vale destacar o tangram, representado em cinco formas diferentes, a saber: tradicional, pitagórico, cruz partida, coração e ovo, conforme Figura 2. 
http://dx.doi.org/10.5902/1984686X35402

Figura 2 - Tangram
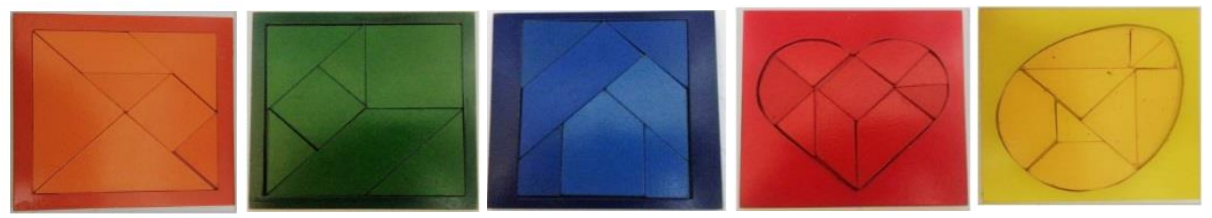

Fonte: Cunha e Franco (2015b, p. 1-3).

O objetivo da atividade com a utilização do Tangram, representado na Figura 2, foi montar as formas (quadrado, retângulo, cruz, coração e ovo) usando uma quantidade finita de peças bidimensionais que seriam disponibilizadas previamente, as quais não poderiam ser sobrepostas ou sobrar. Esta atividade possibilita trabalhar também a identificação de cada uma das representações do Tangram com os deficientes visuais (CUNHA; FRANCO, 2015b).

Com relação ao número de peças presentes nas 5 formas diferentes do tangram (Figura 2), constatamos que três destes (Figura 2 - a, b e c) possuíam 7 peças, e dois deles (Figura 2, c e d) continham 9 peças. No tangram tradicional, conforme Figura 2 (a), as 7 peças eram compostas por representações de: 2 triângulos retângulos grandes, 1 triângulo retângulo médio, 2 triângulos retângulos pequenos, 1 quadrado e 1 paralelogramo. Já no tangram pitagórico, ver Figura 2 (b), compunham as 7 partes: 2 triângulos retângulos médios, 2 triângulos retângulos pequenos, 1 quadrado grande, 1 quadrado pequeno e1 paralelogramo. O terceiro tangram, com 7 componentes, era o chamado de cruz e possuía representações de: 2 trapézios retângulos pequenos, 1 trapézio retângulo médio, 1 trapézio retângulo grande, 2 triângulos retângulos e 1 pentágono. No modelo coração, de 9 peças, destacam-se: 1 círculo completo dividido em setores circulares, sendo 3 setores circulares de $90^{\circ}$ ( $1 / 4$ do círculo) e 2 de $45^{\circ}$ (1/8 do círculo), 1 quadrado, 1 triângulo retângulo isósceles, 1 trapézio retângulo e 1 paralelogramo. Já o de formato ovo constitui-se dos seguintes elementos: 2 setores circulares de $45^{\circ}$ ( $1 / 8$ da circunferência), 2 triângulos retângulos isósceles médios, 1 triângulo retângulo isósceles pequeno, 2 peças com formato que se assemelha ao trapézio isósceles, entretanto, com a base maior curvilínea e 2 outras peças que lembram triângulos retângulos com a hipotenusa curvilínea.

$\mathrm{Na}$ explanação, Cunha e Franco (2015b) mencionam que, dentre os conceitos matemáticos possíveis de serem trabalhados com os alunos deficientes visuais, destacamse as noções de translação, rotação e reflexão. É possível trabalhar as propriedades das figuras geométricas presentes nos variados tipos de tangram descritos (Figura 2), sendo 
que o professor pode levar os tangrans já construídos ou propor uma aula em que possa realizar a construção juntamente com os alunos e trabalhar as propriedades de cada uma das figuras, ressaltando seus nomes e propriedades relacionadas a ângulos internos e externos, medidas de comprimento e quantidade de lados.

A segunda proposta apresentada por Cunha e Franco (2016) é o Cubo soma que pode ser observado na Figura 3:

Figura 1 - Cubo soma

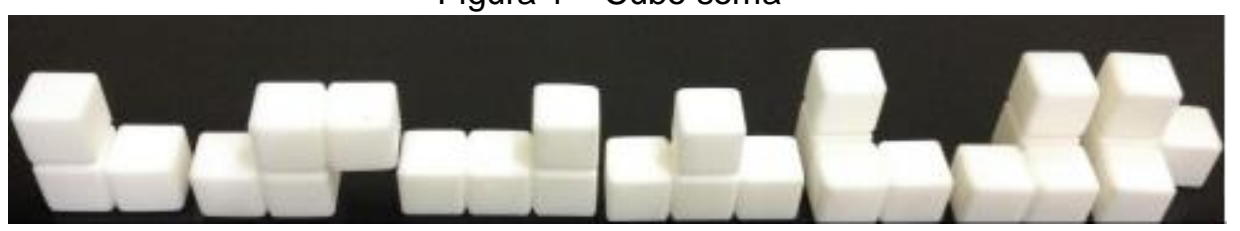

Fonte: Cunha e Franco (2015a, p. 1).

O cubo soma é um quebra-cabeça tridimensional que dispõe de 7 policubos (Figura 3), sendo um tricubo e os outros 6 tetracubos (CUNHA; FRANCO, 2015a). Considerado um tangram tridimensional, pode possibilitar o desenvolvimento de memória, concentração, coordenação, habilidade espacial, pensamento crítico, solução de problemas, e agilidade mental, tanto para alunos cegos quanto videntes.

Como uma adaptação do material representado na Figura 3 para os alunos cegos e com baixa visão, tendo em vista facilitar a organização e o manuseio, Cunha e Franco (2015a) criaram uma base de sustentação no formato geométrico de um cubo, com o intuito de dar apoio para o manuseio com maior facilidade e agilidade, conforme representado na Figura 4.

Figura 4 - Cubo soma adaptado para deficientes visuais

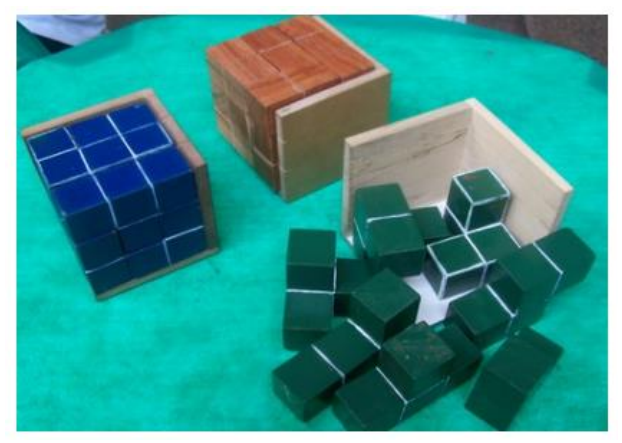

Fonte: Cunha e Franco (2015a, p. 2).

Nesta adaptação coloriram o material para auxiliar os alunos com baixa visão. Além disso, demarcaram cada policubo, de modo a possibilitar a identificação dos cubos 
menores, tanto no tricubo, para identificar os três cubos existentes, quanto nos tetracubos, para percepção dos seis cubinhos. Assim, por meio da percepção tátil ou da visão residual há a possibilidade de descobrir que as 7 peças montadas formam 1 cubo com 27 cubinhos menores (Figura 4). O professor pode com este material trabalhar a noção de área, volume, as propriedades específicas do cubo, além de explorar a percepção espacial dos alunos com deficiência visual. Tal exploração pode ser realizada individualmente ou em pequenos grupos, em que o professor pode valer-se da interação entre os alunos como forma de trabalhar e institucionalizar os conceitos matemáticos que almeja explorar com a utilização desse material.

A torre de Hanói ${ }^{1}$ é formada por uma base com três pinos e uma certa quantidade de discos de diferentes diâmetros empilhados (ordem decrescente) em um dos pinos, conforme Figura 5. O objetivo é transferir os discos para um dos outros dois pinos com a menor quantidade possível de movimentos.

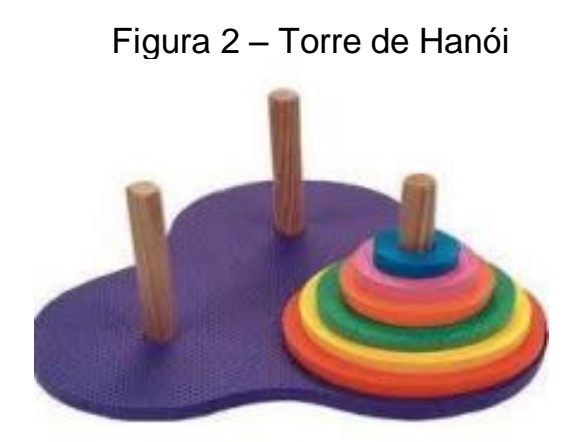

Fonte: Souza (2014, p. 64).

Com a utilização deste material é possível trabalhar com "representação dos conjuntos numéricos e relação entre conjuntos" (SOUZA, 2014, p. 60), bem como o estudo de progressão geométrica nas sequências encontradas e função exponencial (MARTINS, 2015). Além disso, Cunha e Franco (2017b) ressaltaram que a "torre de Hanói estimula o raciocínio na percepção de padrões, no pensamento recorrente e na sistematização que leva ao pensamento abstrato". Diante disso, podemos aferir que este é um material que pode abrir um leque de possibilidades para os professores de Matemática, tanto em sala de aula regular quanto no contexto do Atendimento Educacional Especializado (AEE) ${ }^{2}$.

Para a aplicação da torre de Hanói com alunos com deficiência visual, Cunha e Franco (2017b) realizaram uma adaptação no material, conforme representado na Figura 6: 
http://dx.doi.org/10.5902/1984686X35402

Figura 6 - Torre de Hanói para deficientes visuais

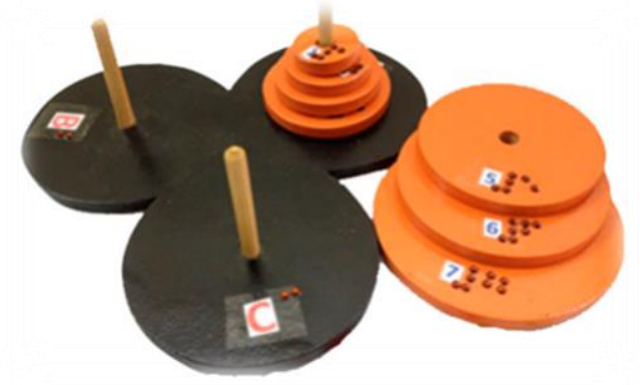

Fonte: Cunha e Franco (2017b, p. 2).

A adaptação consistiu em acrescentar números arábicos nos discos, escritos em Braille e em tinta, aspecto que contempla tanto os alunos com deficiência visual quanto os videntes. O objetivo foi fornecer mais um elemento que pudesse auxiliar os alunos na identificação dos variados tamanhos dos discos. Além disso, acrescentou-se letras na base, escritas em Braille e em tinta, próximo aos pinos, facilitando o reconhecimento e a movimentação nos mesmos. Tais adaptações foram realizadas tanto com a utilização de fontes ampliadas para as letras e os números, isto para os estudantes com baixa visão, quanto a apresentação em Braille para os estudantes cegos, as quais estão representadas ao lado direito dos números e letras escritos em tinta, conforme Figura 6.

Outro material que pode contribuir com o processo de ensino e aprendizagem de alunos com deficiência visual, no contexto da sala de aula é o cubo mágico, representado na Figura 7.

Figura 3 - Cubo mágico adaptado para estudantes com deficiência visual
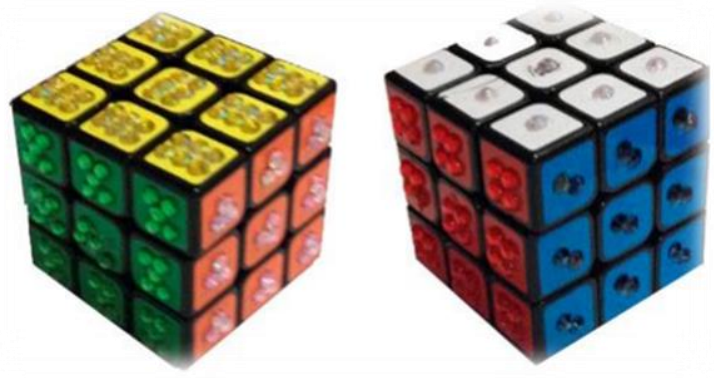

Fonte: Cunha e Franco (2017a, p. 2).

O cubo mágico possui 6 faces, cada face de uma cor: verde, vermelha, azul, laranja, amarela e branca, sendo que a face branca é oposta a amarela, a vermelha oposta a laranja e a verde oposta a azul. O objetivo do jogo é, ao identificar que as peças estão embaralhadas, completar cada face com todas as peças da mesma cor. Com a utilização 
http://dx.doi.org/10.5902/1984686X35402

deste material, segundo Grimm (2016), é possível trabalhar conceitos de álgebra, dentre estes a teoria de grupos e grupos de permutações, assuntos discutidos no Ensino Superior e na Educação Básica. Pode, igualmente, ser proveitoso no âmbito das funções.

Para os alunos com deficiência visual, Cunha e Franco (2017a) colaram autoadesivos de cristais em quantidades de 1 a 6 em cada uma das peças que compõem as faces do cubo, os autoadesivos eram das mesmas cores que as faces correspondentes do cubo, por exemplo, na face de cor branca, foram colados em cada uma das peças um autoadesivo de cristal de cor branca, conforme nota-se na Figura 7. Isto pode facilitar para os alunos cegos se guiarem pela quantidade, já os alunos com baixa visão, além de poderem guiarse pela quantidade de cristais, poderão também ter como referência a cor mais brilhante dos cristais para a identificação das peças.

Os materiais que foram apresentados constituem estratégias que podem contribuir com o processo de ensino e aprendizagem, entretanto, o despertar do lúdico dependerá dos alunos que estão manuseando os materiais e do desenvolvimento do planejamento que o professor realizou previamente para aplicar tais materiais, bem como a mediação na realização da atividade. Ademais, o professor, a partir do seu contexto de atuação poderá organizar, reestruturar e adaptar os materiais e atividades que possam institucionalizar os conhecimentos que foram sendo indicados em cada material, isto de maneira que possibilite estimular a participação autônoma dos alunos deficientes visuais e videntes.

Além desses materiais e considerando-se que vivemos em uma sociedade tecnológica e que a escola possui uma função social de educar diferentes sujeitos com as mais distintas especificidades, faz-se necessário levar para o âmbito das salas de aulas as tecnologias, as quais, neste caso específico, podem ser trabalhadas com estudantes com deficiência visual. Diante disso, apresentaremos, na próxima seção, jogos digitais, os quais podem ser utilizados como estratégia lúdica pelos professores para o desenvolvimento do processo de ensino e aprendizagem com alunos deficientes visuais.

\section{Jogos matemáticos digitais para deficientes visuais}

Atualmente, as tecnologias assistivas dispõem de inúmeros programas destinados às pessoas com deficiência visual, englobando os mais variados recursos de informática e, para além disso, adaptações que podem vir a proporcionar maior autonomia para os seus utilizadores. Bersche e Tonolli (2006, p.1) definem este tipo de tecnologia como sendo um 
"arsenal de recursos e serviços que contribuem para proporcionar ou ampliar habilidades funcionais de pessoas com deficiência". Neste contexto, um dos softwares mais conhecidos pela comunidade de pessoas com deficiência visual é o Dosvox. Segundo Borges (2009), o Dosvox é um sistema integrado, que conta com cerca de noventa outros programas, os quais permitem que sejam exploradas pelos deficientes visuais várias funcionalidades dos computadores, sendo que este programa utiliza a descrição em áudio de inúmeras funcionalidades do computador. O Dosvox conta com vários jogos, nas seguintes categorias: Jogo da forca, Jogo da memória de letras, Jogo de mistura de sons, Jogavox, Jogos educativos, Jogos de RPG, Passatempo, Desafios, Oráculos.

Tendo em vista o ensino e a aprendizagem da Matemática, realizamos um levantamento no sistema Dosvox e detectamos o Jogavox, um programa que permite jogar, criar e editar jogos digitais adaptados para cegos. Possui três categorias de jogos, a saber: Caos, que são os jogos recém-chegados que necessitam passar por avaliação; Gaia, os que estavam na categoria Caos e, após avaliações e correções, foram melhorados; e, na última, Olimpo, encontram-se os jogos que foram avaliados com maior "maturidade".

Na categoria Gaia, há o Jogo dos números, o contexto deste jogo é o seguinte: uma garotinha, chamada Yasmin, precisa aprender os números de 1 a 10 para então levar um cesto de gostosuras para sua avó. O intuito pedagógico deste jogo é o de ensinar a contar a partir de perguntas e respostas. Já na categoria Caos, há os jogos que estão descritos no Quadro 1, a seguir:

Quadro 1 - Jogos disponíveis no Jogavox na categoria Caos

\begin{tabular}{|c|c|}
\hline Nome do jogo & Breve descrição \\
\hline Figuras geométricas & $\begin{array}{l}\text { O jogo tem como desafio perguntas sobre figuras } \\
\text { geométricas, tais como triângulo, retângulo, } \\
\text { hexágono, entre outras. }\end{array}$ \\
\hline Continha & $\begin{array}{l}\text { O jogo tem como desafio algumas operações de } \\
\text { adição simples e o jogador deve apresentar o } \\
\text { resultado. }\end{array}$ \\
\hline Tabuada 2 & $\begin{array}{l}\text { O jogo envolve a operação de multiplicação, dos } \\
\text { números de } 1 \text { a } 9 \text { multiplicados por } 2 \text {, sendo que os } \\
\text { jogador(es) deve(m) digitar as respostas das } \\
\text { operações. }\end{array}$ \\
\hline Mundo das continhas & $\begin{array}{l}\text { O jogo apresenta algumas questões que envolvem } \\
\text { as quatro operações matemáticas. }\end{array}$ \\
\hline Jogo de Matemática o X da questão & $\begin{array}{l}\text { O jogo apresenta diferentes questões sobre vários } \\
\text { conteúdos matemáticos, tais como porcentagem, } \\
\text { raciocínio lógico e as quatro operações. Cada } \\
\text { questão apresenta quatro alternativas para serem } \\
\text { escolhidas pelo(s) jogador(es). }\end{array}$ \\
\hline
\end{tabular}


http://dx.doi.org/10.5902/1984686X35402

Quadro 1 - Jogos disponíveis no Jogavox na categoria Caos

\begin{tabular}{|c|c|}
\hline Nome do jogo & Breve descrição \\
\hline Jogo de lógica & $\begin{array}{l}\text { O jogo aborda questões que envolvem raciocínio } \\
\text { lógico, por exemplo, localizar um número numa } \\
\text { determinada sequência numérica. }\end{array}$ \\
\hline Mundo das continhas & $\begin{array}{l}\text { O jogo apresenta algumas questões que envolvem } \\
\text { as quatro operações matemáticas. }\end{array}$ \\
\hline Jogo de Matemática o X da questão & $\begin{array}{l}\text { O jogo apresenta diferentes questões sobre vários } \\
\text { conteúdos matemáticos, tais como porcentagem, } \\
\text { raciocínio lógico e as quatro operações. Cada } \\
\text { questão apresenta quatro alternativas para serem } \\
\text { escolhidas pelo(s) jogador(es). }\end{array}$ \\
\hline Jogo de lógica & $\begin{array}{l}\text { O jogo aborda questões que envolvem raciocínio } \\
\text { lógico, por exemplo, localizar um número numa } \\
\text { determinada sequência numérica. }\end{array}$ \\
\hline Jogo de lógica & $\begin{array}{l}\text { O jogo aborda questões que envolvem raciocínio } \\
\text { lógico, por exemplo, localizar um número numa } \\
\text { determinada sequência numérica. }\end{array}$ \\
\hline
\end{tabular}

Fonte: Dados dos próprios autores.

Vale ressaltar que estes jogos, descritos no Quadro 1, ainda estão na categoria Caos e, portanto, não passaram por uma revisão criteriosa. Além disso, existem jogos no Jogavox, elaborados também em uma perspectiva educativa que envolvem outras áreas do conhecimento, como Física, Língua Portuguesa e Ciências. Também jogos de aventura e de enigmas, que não necessariamente estão relacionados ao ensino e à aprendizagem de determinados conteúdos escolares, por exemplo.

No sistema Dosvox, na categoria dos Jogos educativos, há o Jogo da Tabuada (Contavox) que a partir do tema futebol explora as quatro operações matemáticas. Existe, também, nesta mesma categoria, o Jogo de adivinhar os números, que explora a noção de antecessor e sucessor, a partir da adivinhação de um número entre 0 e 99. A única dica é se esse número é maior ou menor do que o que o jogador digitar. Na categoria Passatempos, encontra-se o Jogo 3x3, em que é apresentado ao jogador uma tabela 3 por 3, contendo 8 números (do 1 ao 8 ) e um espaço vazio, o jogador deve mover os números usando o cursor até organizá-los em ordem crescente. Na categoria Desafios, encontra-se o Jogo da senha: o jogador deve descobrir uma senha numérica, escolhida aleatoriamente, contendo quatro dígitos distintos, com os algarismos que vão do 0 ao 5.

Com a utilização destes jogos, o professor pode trabalhar com as noções de números, quatro operações, noção de antecessor e sucessor, probabilidade, aleatoriedade, entre outros assuntos, a postura do professor será de mediador do conhecimento, pois serão os alunos que executarão os jogos e tentarão alcançar o objetivo de vencer o jogo. Segundo 
Silva (2017, p. 124), "os jogos digitais adaptados trazem para a vida da pessoa com deficiência mais diversão e podem proporcionar aprendizagem através do lúdico". Esta interação com os jogos digitais pelas pessoas com deficiência visual ainda é recente, mas o sistema Dosvox apresenta uma nova possibilidade para o processo de ensino e aprendizagem, que é a criação de jogos neste ambiente, pelos próprios usuários deficientes visuais, tendo em vista que o programa conta com a descrição em áudio de todas os comandos que o usuário realiza, possibilitando maior autonomia e interatividade.

Permanecendo no âmbito das tecnologias educacionais, vale destacar o Objeto de Aprendizagem Blind, Educationand Mathematics (BEM). Este jogo foi desenvolvido por Dantas, Pinto e Sena (2013), com o intuito de trabalhar as quatro operações matemáticas, isto é, adição, subtração, multiplicação e divisão. A Figura 8 representa a interface inicial do jogo.

Figura 4 - Jogo BEM

\begin{tabular}{|c|c|c|c|c|c|}
\hline 10 & 8 & 2 & 8 & 8 & Opçōes de jogo \\
\hline 5 & 6 & 4 & 8 & 10 & Jogo de Subtrair \\
\hline 7 & 5 & 9 & 0 & 8 & Jogo de Dividir \\
\hline 4 & 1 & 2 & 3 & 9 & \multirow{3}{*}{$\begin{array}{r}\text { Tempo de Jogo } \\
\text { o::00:04 }\end{array}$} \\
\hline \multicolumn{5}{|c|}{ Quaks sâo os números? } & \\
\hline \multicolumn{5}{|c|}{$?+?=16$} & \\
\hline
\end{tabular}

Fonte: Dantas, Pinto e Sena (2013, p. 441).

Vale ressaltar que não há um consenso sobre a definição de Objeto de Aprendizagem, mas para Wiley (2000, p. 3) é "qualquer recurso digital que possa ser reutilizado para o suporte ao ensino". Com esta percepção de Objeto de Aprendizagem, destacamos que o BEM apresenta como interface um tabuleiro com 4 linhas e 5 colunas, conforme Figura 8, nas quais são dispostos números, gerados de maneira aleatória, após o jogador escolher a operação matemática que deseja jogar.

O jogo consiste em apresentar um número que será o resultado da operação. Por exemplo, na Figura 8, aparece o número 16 e a operação escolhida foi a de adição; então, o jogador indicará dois números na tabela, cuja soma seja 16. À medida que ele irá percorrendo as teclas "up", “down", "left” e "rigth”, mencionar-se-á, em áudio, o número 
correspondente. Ao final do jogo, indicar-se-á, em áudio, o tempo decorrido desde o início da partida. Este jogo possibilita aos alunos fixarem as quatro operações, além de desenvolverem estratégias que permitam compreender as operações inversas.

Outro recurso educacional, voltado tanto para alunos cegos quanto surdos, em uma perspectiva lúdica, é Poligonopolis. Trata-se de uma cidade onde os elementos e personagens devem ser construídos a partir de polígonos. Este jogo foi construído por Primo et al. (2016) com o objetivo de facilitar a aprendizagem de alguns conceitos geométricos, tais como definir, classificar e reconhecer os elementos de um polígono. Há três níveis que o jogador pode atingir, de acordo com as moedas do conhecimento que adquire ao acertar a atividade: no nível inicial, ele possui um papel de visitante; no nível dois, é considerado um explorador; e no nível três passa a ser um empreendedor. A gamificação é uma estratégia para elevar a motivação e o engajamento em relação a um certo conteúdo, além de possibilitar tanto a ressignificação quanto a afirmação do papel social de determinados conceitos matemáticos. $\mathrm{O}$ jogo Poligonopolis utiliza o ambiente de aprendizagem Moodle-bilíngue (Moobi) de um projeto de representação gráfica de uma Universidade Federal. Primo et al. (2016, p. 4) afirmam que este recurso educacional possui "uma tela de apresentação que convida à imersão na narrativa e o Objeto de Aprendizagem (AO) correspondente à unidade temática estudada". Há ferramentas que auxiliam surdos e cegos, dentre estas: o vídeo Libras; a versão com texto Braille para as cartas; o polígono para impressão em relevo (Figura 9 - b); o Geoplano (Figura 9 - a) e o Tangram físico para substituir o aplicativo Web presente no jogo.

Figura 5 - Alternativas táteis para aplicativos gamificados do Poligonopolis

(a)

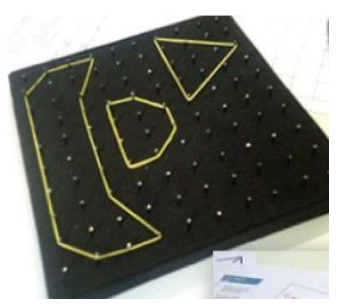

(b)

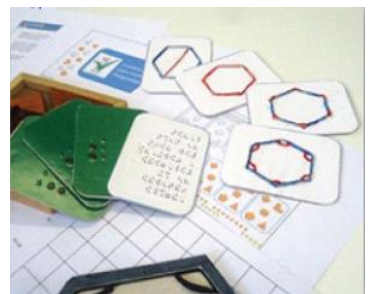

Fonte: Primo et al. (2016, p. 7).

Diante das possibilidades de utilização dos jogos digitais, concordamos com Siaulys (2010): as crianças com deficiência visual necessitam de estímulos diferenciados para seu desenvolvimento sensório-motor e sua aprendizagem de uma maneira mais participativa, atuante e desafiadora.Com isso, o professor pode valer-se não apenas de jogos digitais, 
mas também de brincadeiras, brinquedos, jogos, ferramentas tecnológicas e materiais especiais adaptados, além da possibilidade de utilizar o sistema Dosvox para a criação de novos jogos.

\section{Considerações finais}

Considerando os inúmeros desafios existentes no processo de ensino e aprendizagem de Matemática numa perspectiva inclusiva, constatamos a necessidade do desenvolvimento de mais pesquisas que possam fomentar atividades que contemplem os deficientes visuais que estejam cursando o Ensino Fundamental e o Ensino Médio. Tendo em vista que são poucos os jogos e as propostas lúdicas, em face da vasta gama de conteúdos matemáticos que compõem o currículo da Educação Básica, faz-se necessário abordar outros conteúdos que são apresentados com um grande apelo visual, como, por exemplo, equações, inequações e funções.

Ao assumirmos que a ludicidade é algo inerente ao indivíduo, que, por conseguinte, dependerá do sujeito, do objeto e do meio em que está inserido, e que o despertar do espírito lúdico, no âmbito educacional, estará atrelado ao como a atividade será proposta, cabe, então, ao professor, planejar as aulas lúdicas, objetivando tornar as atividades instigantes, prazerosas, participativas e desencadeadoras de novas aprendizagens, considerando as especificidades da sua turma e dos seus alunos.

Outro aspecto importante, ao propor atividades lúdicas, é que o professor possa ter criatividade, para propiciar a exploração do meio em que seus alunos estão inseridos, seja este social ou escolar. Ademais, deve dispor de tato pedagógico, para mediar, propor desafios e considerar o ritmo de interação e aprendizagem de cada um, pois a sala de aula é constituída de heterogeneidade, são diferentes os modos de aprender e expressar aquilo que aprendeu. Deve, ainda, ser um incentivador de novas descobertas, deixando a cargo dos estudantes o papel principal do processo de ensino e aprendizagem.

Por fim, espera-se que esta pesquisa contribua com a prática de docentes que estejam em busca da inclusão de alunos com deficiência visual, e possa, igualmente, contribuir com os estudos e discussões voltados à inclusão das mais diversas NEE, bem como o ensino e a aprendizagem pautados em aspectos lúdicos nos diversos níveis escolares. Ademais, almeja-se que os materiais aqui apresentados possam adentrar os espaços escolares e facilitar o processo de ensino e aprendizagem da Matemática, potencializando a criatividade 
dos sujeitos ao utilizarem tais jogos e fomentando a criação de outras estratégias lúdicas, pois são muitas as possibilidades.

\section{Referências}

ALMEIDA, Paulo Nunes de. Educação Lúdica: técnicas e jogos pedagógicos. São Paulo: Loyola, 1998.

ÁVILA, Marcos et. al. As condições de saúde ocular no Brasil: 2015. São Paulo: Conselho Brasileiro de Oftalmologia, 2015. Disponível em:

http://www.cbo.net.br/novo/publicacoes/Condicoes_saude_ocular_IV.pdf . Acesso em: 10 set. 2018.

BERSCHE, Rita; TONOLLI, José Carlos. Introdução ao conceito de tecnologia assistiva e modelos de abordagem da deficiência. 2006. Disponível em: http://www.bengalalegal.com/tecnologia-assistiva. Acesso em: 24 ago. 2018.

BORGES, José Antonio dos Santos. Do Braille ao Dosvox: diferenças nas vidas dos cegos brasileiros. Tese (Doutorado em Engenharia de Sistemas e Computação). Universidade Federal do Rio de Janeiro, Rio de Janeiro: UFRJ/COPPE, 2009.

BRASIL. Decreto no 5.296 de 2 de dezembro de 2004. Regulamenta a Lei n. 10.048, de 8 de novembro de 2000. Diário Oficial da União. Brasília. 2004. Disponível em: www.planalto.gov.br/ccivil_03/_Ato2004-2006/2004/Decreto/D5296.htm. Acesso em: 25 ago. 2018.

BRASIL. Ministério da Educação. Matrículas e Infraestrutura. 2016. Disponível em: http://qedu.org.br/brasil/censoescolar?year $=2017$ \&dependence $=0$ \&localization $=0$ \&education_stage $=0$ \&item $=$. Acesso 27 out. 2018.

BRASIL. Ministério da Educação. Política Nacional de Educação Especial na Perspectiva Inclusiva. Brasília, 2008. Disponível em: http://portal.mec.gov.br/arquivos/pdf/politicaeducespecial.pdf. Acesso em 27 out. 2018.

BRASIL. Ministério da Educação. Secretaria da Educação Especial. Projeto escola viva: garantindo o acesso e permanência de todos os alunos na escola. Brasília: MEC, SEE, 2000.

BRASIL. Ministério da Educação. Secretaria de Educação Especial. Projeto Escola Viva: garantindo o acesso e permanência de todos os alunos na escola. Brasília: MEC, SEE, 2005.

BRASIL. Ministério da Educação. Secretaria de Educação Fundamental. Secretaria de Educação Especial. Parâmetros Curriculares Nacionais: Adaptações Curriculares. Brasília: MEC, SEF, SEESP, 1998.

CUNHA, Kátia Machinez; FRANCO, Alfred Sholl. Desafio 3D: cubo soma. In: Roteiros de 
Práticas em Neurociências. 2015a. Disponível em: www.cienciasecognicao.org/min/wpcontent/uploads/2015/09/CUBO-SOMA.pdf. Acesso em: 27 ago. 2018.

CUNHA, Kátia Machinez; FRANCO, Alfred Sholl. Desafios 2D: tangrans. In: Roteiros de Práticas em Neurociências. 2015b. Disponível em: www.cienciasecognicao.org/min/wpcontent/uploads/2015/09/TANGRAM.pdf. Acesso em: 27 ago. 2018.

CUNHA, Kátia Machinez; FRANCO, Alfred Sholl. Cognition and logic: adaptation and application of inclusive teaching materials for hands-on workshops. Journal of Research in Special Educational Needs. v. 16, n. 1, p. 696-700, 2016. Disponível em: https://onlinelibrary.wiley.com/doi/epdf/10.1111/1471-3802.12203. Acesso em: 27 ago. 2018.

CUNHA, Kátia Machinez; FRANCO, Alfred Sholl. Cubo mágico: Rubik's. In: Roteiros de Práticas em Neurociências - 2017. 2017a. Disponível em: www.cienciasecognicao.org/min/wp-content/uploads/2017/04/Manual-Cubo-M\%C3\%A1gicoAdaptado.pdf. Acesso em: 27 ago. 2018.

CUNHA, Kátia Machinez; FRANCO, Alfred Sholl. Desafio indução: torre de Hanói. In: Roteiros de Práticas em Neurociências - 2017. 2017b. Disponível em: www.cienciasecognicao.org/min/wp-content/uploads/2017/04/TORRE-DE-HANÓI.pdf. Acesso em: 27 ago. 2018.

DANTAS, André L. P.; PINTO, Gabriela, R. P. R.; SENA, Claudia P. S. Apresentando o BEM: um objeto de aprendizagem para mediar o processo educacional de crianças com deficiência visual e videntes nas operações básicas de Matemática. Anais... 2013. Disponível em: www.br-ie.org/pub/index.php/sbie/article/view/2522. Acesso em: 17 ago. 2018.

GRIMM, Luis Gustavo Hauff Martins. Cubo Mágico: propriedades e resoluções envolvendo álgebra e teoria de grupos. Dissertação (Mestrado Profissional em Matemática). Universidade Estadual Paulista Júlio de Mesquita Filho. Rio Claro: Unesp, 2016. Disponível em: https://repositorio.unesp.br/bitstream/handle/11449/144192/grimm_Ighm_me_rcla_int.pdf?seq uence=4\&isAllowed=n. Acesso em: 27 ago. 2018.

HUIZINGA, JOHAN. Homo Ludens: O jogo como elemento da cultura. Ed. 8. São Paulo: Perspectiva, 2014.

LOPES, Maura Corcini; FABRIS, Eli Henn. Inclusão e Educação. Belo Horizonte: Autêntica, 2013.

LUCKESI, Cipriano. Ludicidade e formação do educador. Revista Entreideias. Salvador, v. 3, n. 2, p. 13-23, jul./dez. 2014. Disponível em:

https://portalseer.ufba.br/index.php/entreideias/article/view/9168/8976. Acesso em: 17 ago. 2018.

MACEDO, Lino de; PETTY, Ana Lúcia Sícole; PASSOS, Norimar Christe. Os jogos: o lúdico na aprendizagem escolar. Porto Alegre: Artmed, 2005. 
MANTOAN, Maria Teresa Eglér. Inclusão escolar: O que é? Por quê? Como fazer? São Paulo: Summus, 2015.

MARTINS, Rosilaine Sanches. O princípio da indução finita e jogos para o ensino de funções. Dissertação (Mestrado Profissional em Matemática). Universidade Estadual Paulista Júlio de Mesquita Filho. São José do Rio Preto: Unesp, 2015. Disponível em: www.athena.biblioteca.unesp.br/exlibris/bd/cathedra/07-04-2016/000863145.pdf. Acesso: 27 ago. 2018.

MASINI, Elcie F. Salzano. O perceber de quem está na escola sem dispor da visão. São Paulo: Cortez, 2013.

MOREIRA, Geraldo Eustáquio. Resolvendo problemas com alunos com Transtornos Globais do Desenvolvimento: desafios e conquistas. Educação Matemática em Revista - RS. v. 1, n. 15, p. 38-48, 2014.

MORGADO, Adriana Santos; SANTOS, Regiane Silva; TAKINAGA, Sofia Seixas. Sugestões de alguns materiais para o ensino e aprendizagem para inclusão. In: MANRIQUE, Ana Lúcia; MARANHÃO, Maria Cristina Souza de Albuquerque; MOREIRA, Geraldo Eustáquio (Org.).

Desafios da Educação Matemática Inclusiva: Práticas. v. 2. São Paulo: Editora Livraria da Física, 2016, p. 85-98.

PIN, Virgínia Perpetuo Guimarães. Jogos de reflexão pura como ferramenta lúdica para a aprendizagem matemática. Dissertação (Mestrado em Educação). Universidade de Brasília, Brasília: UnB, 2016.

PRIMO, Lane et. al. Poligonopolis: Prototype of accessible and gamified learning object to teach Geometry. Piscataway. The Institute of Electrical and Electronics Engineers (IEEE). Conference Proceedings, out. 2016, p. 1-9.

SÁ, Sérgio. Feche os olhos para ver melhor: os limites dos sentidos e os sentidos dos limites. Barueri: Sá Editora, 2004.

SIAULYS, Mara Olimpia de Campos. Importância do Brincar no Desenvolvimento da Criança com Deficiência Visual. In: SAMPAIO, Marcos Wilson et al. Baixa visão e cegueira: os caminhos para a reabilitação, a educação e a inclusão. Rio de Janeiro: Cultura Médica - Guanabara Koogan, 2010, p. 309-326.

SILVA, Wesley Pereira da. Jogos digitais adaptados para estudantes com deficiência visual: estudo das habilidades cognitivas no Dosvox. Dissertação (Mestrado em Educação). Universidade de Brasília, Brasília: UnB, 2017.

SOUZA, Adriane Eleutério. O lúdico associado à resolução de problemas e jogos no ensino e aprendizagem de funções: uma abordagem diferenciada. Dissertação (Mestrado em Ensino em Ciência e Tecnologia). Universidade Tecnológica Federal do Paraná. Ponta Grossa: UTFP, 2014. 
WILEY, David A. Connecting learning objects to instructional design theory: A definition, a metaphor, and a taxonomy. In: WILEY, David A. (Org.) The Instructional Use of

Learning Objects. 2000, p. 1-35. Disponível em:

http://reusability.org./read/chapters/wiley.doc. Acesso em: 17 ago. 2018.

\section{Notas finais}

${ }^{1}$ Elaborada por Edouard Lucas e comercializada como um brinquedo em 1883.

${ }^{2}$ Compreendido como o conjunto de atividades, recursos de acessibilidade e pedagógicos, organizados institucional e continuamente, prestado de forma complementar ou suplementar à formação dos alunos (BRASIL, 2011).

\section{Correspondência}

Érica Santana Silveira Nery - Universidade de Brasília, Faculdade de Educação, Campus Universitário Darcy Ribeiro.

CEP: 70910-900.

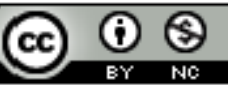

This work is licensed under a Creative Commons Attribution-NonCommercial 4.0 International (CC BY-NC 4.0)

Modalidade do artigo: Relato de pesquisa ( ) Revisão de Literatura ( X ) 